\title{
A systematic review of trends and patterns of congenital heart disease in children in Nigeria from 1964-2015.
}

\author{
Mohammed Abdulkadir ${ }^{1}$, Zainab Abdulkadir²
}

1. Department of Paediatrics and Child Health, University of Ilorin/ University of Ilorin Teaching Hospital, Ilorin, Kwara State, Nigeria

2. Department of Obstetrics and Gynaecology, University of Ilorin Teaching Hospital, Ilorin, Kwara State, Nigeria

\begin{abstract}
Background: Congenital heart diseases cause significant childhood morbidity and mortality. Several restricted studies have been conducted on the epidemiology in Nigeria. No truly nationwide data on patterns of congenital heart disease exists.

Objectives: To determine the patterns of congenital heart disease in children in Nigeria and examine trends in the occurrence of individual defects across 5 decades.

Method: We searched PubMed database, Google scholar, TRIP database, World Health Organisation libraries and reference lists of selected articles for studies on patterns of congenital heart disease among children in Nigeria between 1964 and 2015. Two researchers reviewed the papers independently and extracted the data. Seventeen studies were selected that included 2,953 children with congenital heart disease.
\end{abstract}

Results: The commonest congenital heart diseases in Nigeria are ventricular septal defect (40.6\%), patent ductus arteriosus $(18.4 \%)$, atrial septal defect $(11.3 \%)$ and tetralogy of Fallot $(11.8 \%)$. There has been a $6 \%$ increase in the burden of VSD in every decade for the 5 decades studied and a decline in the occurrence of pulmonary stenosis. Studies conducted in Northern Nigeria demonstrated higher proportions of atrial septal defects than patent ductus arteriosus.

Conclusions: Ventricular septal defects are the commonest congenital heart diseases in Nigeria with a rising burden.

Keywords: Heart disease, congenital; epidemiology; patterns; trends; Nigeria.

DOI: http://dx.doi.org/10.4314/ahs.v16i2.5

Cite as: Abdulkadir M, Abdulkadir Z. A systematic review of trends and patterns of congenital heart disease in children in Nigeria from 1964-2015. Afri Health Sci 2016;16(2): 367-377. http:/ / dx.doi.org/10.4314/ abs.v16i2.5

\section{Introduction}

Congenital heart disease is defined as a gross structural abnormality of the heart or intrathoracic great vessels that is actually or potentially of functional significance. ${ }^{1}$ Generally, conditions that are of no functional significance such as persistent left superior caval vein are excluded from this definition. ${ }^{1}$ They are a diverse group of disorders with varying aetiology, symptomatology, severity and outcome.

Globally, the prevalence of congenital heart diseases among newborns and infants vary between 3 and 14 per

\section{Corresponding author:}

Mohammed Abdulkadir,

Department of Paediatrics and Child Health,

University of Ilorin/ University of Ilorin

Teaching Hospital, Ilorin, Kwara State, Nigeria

I Old Jebba Road Ilorin Kwara 240231

Nigeria

Email: docmohng@yahoo.com
1000 live births., ${ }^{2,3}$ In Nigeria, congenital heart diseases are seen in 3.5 out of every 1000 live births. ${ }^{4}$ Data on the spectrum of common congenital heart diseases in Nigeria has generally been sketchy with wide variations in relative frequencies.

Initial studies on spectrum of congenital heart diseases in Nigeria by Gupta and Antia (1966), ${ }^{4}$ Antia and Williams $(1971)^{5}$ and Antia (1974) ${ }^{6}$ were necropsy and/or clinical based. Using necropsy studies in determining spectrum has an obvious limitation of dealing predominantly with severe/ fatal conditions. Nevertheless they still remain useful in providing definitive diagnoses ${ }^{6}$ Clinical findings are not always a true reflection of the underlying condition and depend very much on the knowledge and skills of the clinician. ${ }^{7}$

Echocardiography has been shown consistently to have a high sensitivity and specificity in diagnosing most cardiac defects. ${ }^{8}$ Echocardiographic services became avail- 
able in Nigeria in the early 1990's and since then there have been several reports on the spectrum of congenital heart disease. However, these reports were largely small isolated studies from individual centres with attendant problems of generalizability. ${ }^{9-15}$ While ventricular septal defects (VSD) were reported as the commonest defects in all such studies, there were wide variations in the relative frequencies of the other congenital heart diseases. ${ }^{9-15}$ Thus, we sought to review all studies on patterns of congenital heart disease diagnosed by detailed clinical examination(inclusive of follow up), angiography, necropsy and/or echocardiography in Nigeria and determine through a trend analysis if there have been any variations in these patterns from 1964 to 2015.

\section{Methods}

A literature search of the PubMed database was conducted for studies published between 1964 and January 2015 using the terms and medical subject terms: heart defects, congenital; heart diseases; Nigeria; and child. A manual search for additional studies was performed using references cited in original study articles and reviews. Additionally, studies were retrieved by searches within Google scholar, TRIP database, African Journals Online and World Health Organisation libraries, including African index medicus. In addition, we contacted well known researchers on congenital heart disease in children in Nigeria for studies that may have been missed. A hand search of local journals was also conducted to ensure no studies were missed. No language restrictions were applied. The study was restricted to human studies and children aged less than fifteen years. The search was conducted in January, 2015. Two authors (MBA and ZAA) conducted the search. All studies were incorporated into an endnote ${ }^{\circledR}$ database.

Eligibility criteria were children aged 0-14 years and confirmation of congenital heart disease diagnosis by detailed clinical evaluation (including follow up) supported with chest radiographs and electrocardiography(for studies prior to 1990); angiography; echocardiography and/or necropsy. Studies were excluded if they were conducted in adults (studies with combined adult and children population were included if the spectrum of cardiac diseases were sufficiently broken down for data for children 0-14 years of age to be retrievable), case reports, ages were not stated, diagnosis was by auscultation alone or the study was conducted in restricted populations such as children with pneumonia, children undergoing heart surgery or children with protein energy malnutrition. Both authors reviewed the studies independently and where discrepancy existed it was resolved by further discussions.

Data was extracted using a data collection tool designed

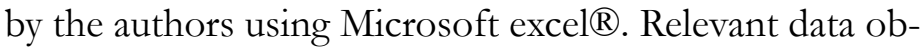
tained included study site and years during which the study was carried out, mean (SD) age of subjects, method(s) of diagnosis, number of cases of congenital heart diseases and the contributions of the individual heart defects. The studies were categorised according to years during which the data was collected into 1964-1969, 1970-1979, 19801989, 1990-1999, 2000-2009, 2010-january 2015 for the purposes of a time trend analysis of the various heart defects. In a situation where recruitment of patients from a particular study extended beyond one of the aforementioned categories, they were placed in the category in which more than half of the data was collected.

The individual heart defects were identified based on the diagnosis as reported in the various manuscripts. Where multiple lesions were found, the major lesion, for example transposition of the great arteries was identified and the patients classified under that diagnosis. Where a single major lesion could not be identified, they were labelled by the multiple lesions together. Frequencies for the various heart defects were added up within the specified time periods and proportions (including 95\% confidence intervals) of the component defects generated. These proportions were used in subsequent analyses. The various data obtained was displayed in standard tables highlighting the component heart defects. A time trend chart was drawn representing the six duration categories and "best fit" lines were used to determine trends.

\section{Results}

We identified 792 articles from an initial search. An additional 49 studies were obtained following search from other sources. In all 16 published studies and one unpublished study (Abdulkadir et al, Ilorin, 2015) met the inclusion and exclusion criteria and were eventually selected. ${ }^{4-6,9,12,14,16-26}$ The PRISMA flowchart summarizing the data collection process is presented in Figure 1. 


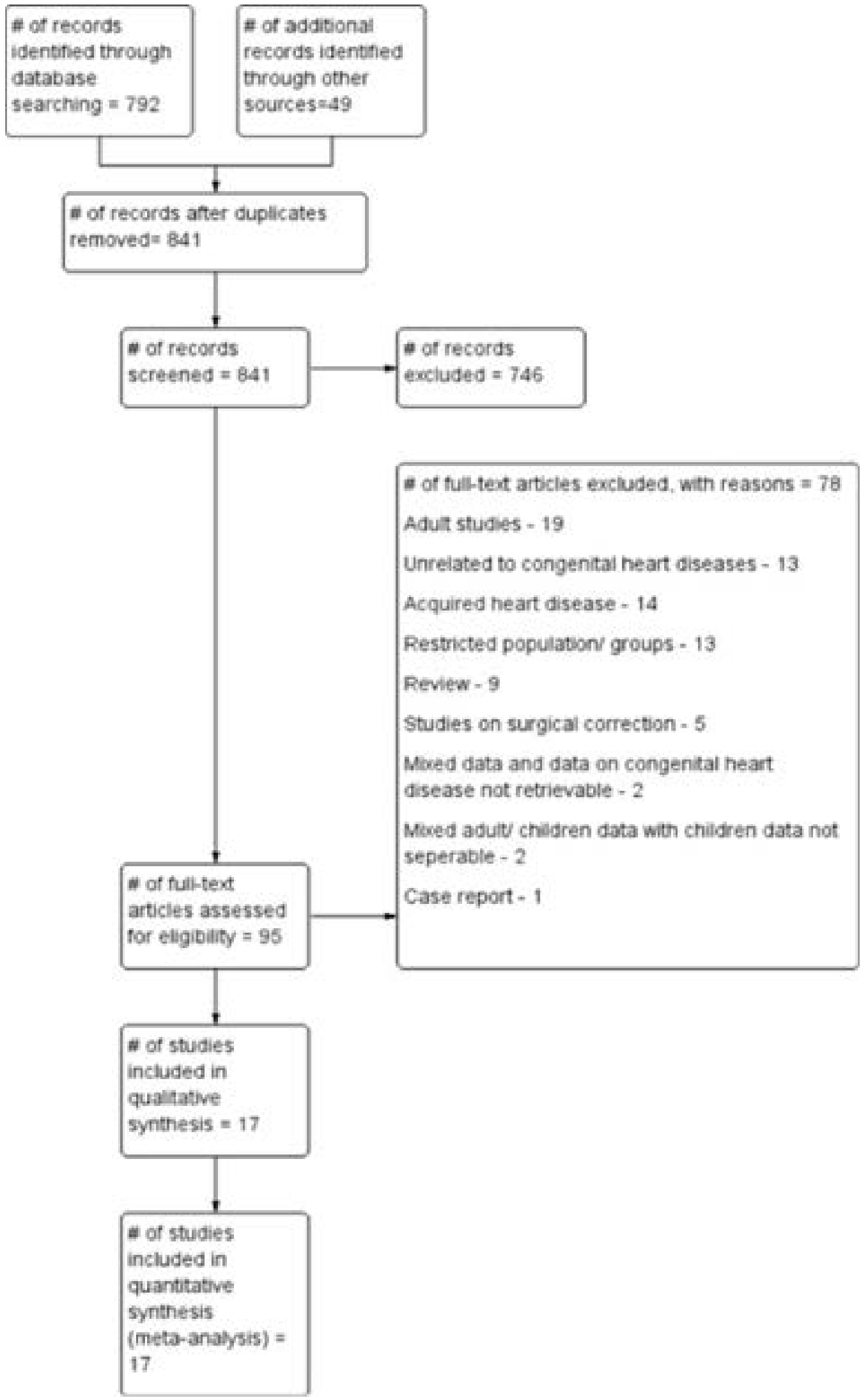

Figure 1: PRISMA flow chart 
All the studies were conducted in children except Sani et $\mathrm{al}^{9}$ however data in their study could be disaggregated to separate the paediatric data. Five of the studies were conducted using clinical, angiographic and/or necropsy data to make the diagnosis of specific congenital heart diseases. ${ }^{4-6,16,17}$ Where clinical data was used the authors demonstrated sufficient evidence including follow up to make the diagnosis of a specific congenital heart disease quite reasonable.
The other studies used echocardiographic findings to make a diagnosis of specific congenital heart diseases.

The studies were conducted in all the geo-political zones in the country except the North-East and South-East regions. The only study from the South East that met the criteria for the study was eventually excluded because of notable inconsistencies in frequencies of individual heart defects. ${ }^{13}$ The spread of the study sites and the number of studies are shown in Figure 2.

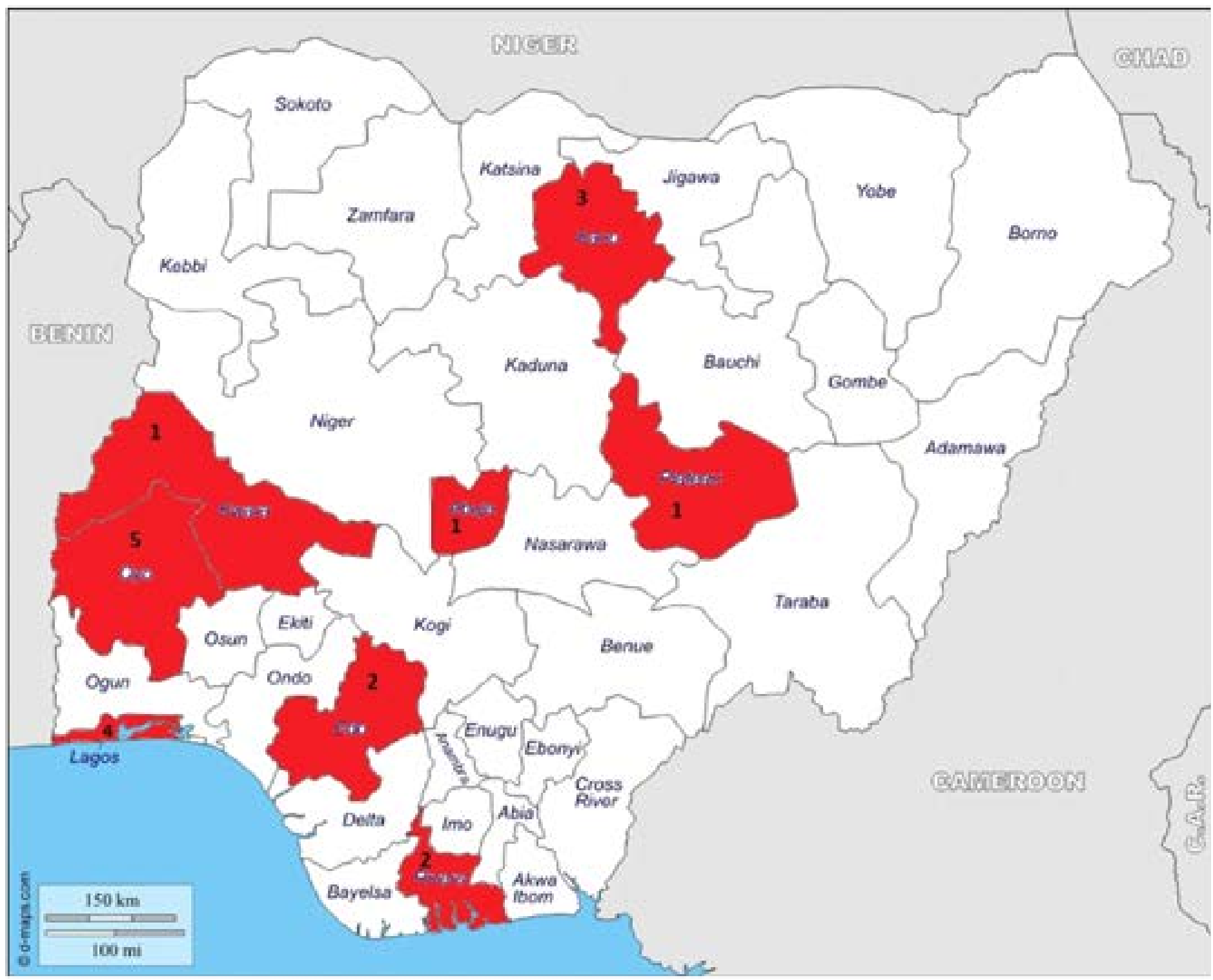

Figure 2: Study sites(in red) in Nigeria with number of studies conducted (One study was conducted in three sites: Edo, Lagos, Abuja)

There was at least one study in each of the specified time periods except 1980-1989. Thus, the period 1980-1989 was excluded from subsequent analyses to avoid a skew of the data. The highest number of studies was conduct- ed in Ibadan with five publications though all the studies were conducted between 1964 and 1981. Table 1 shows a summary of the included studies and their major findings. 
Table 1: Distribution of individual congenital heart diseases in the studies reviewed

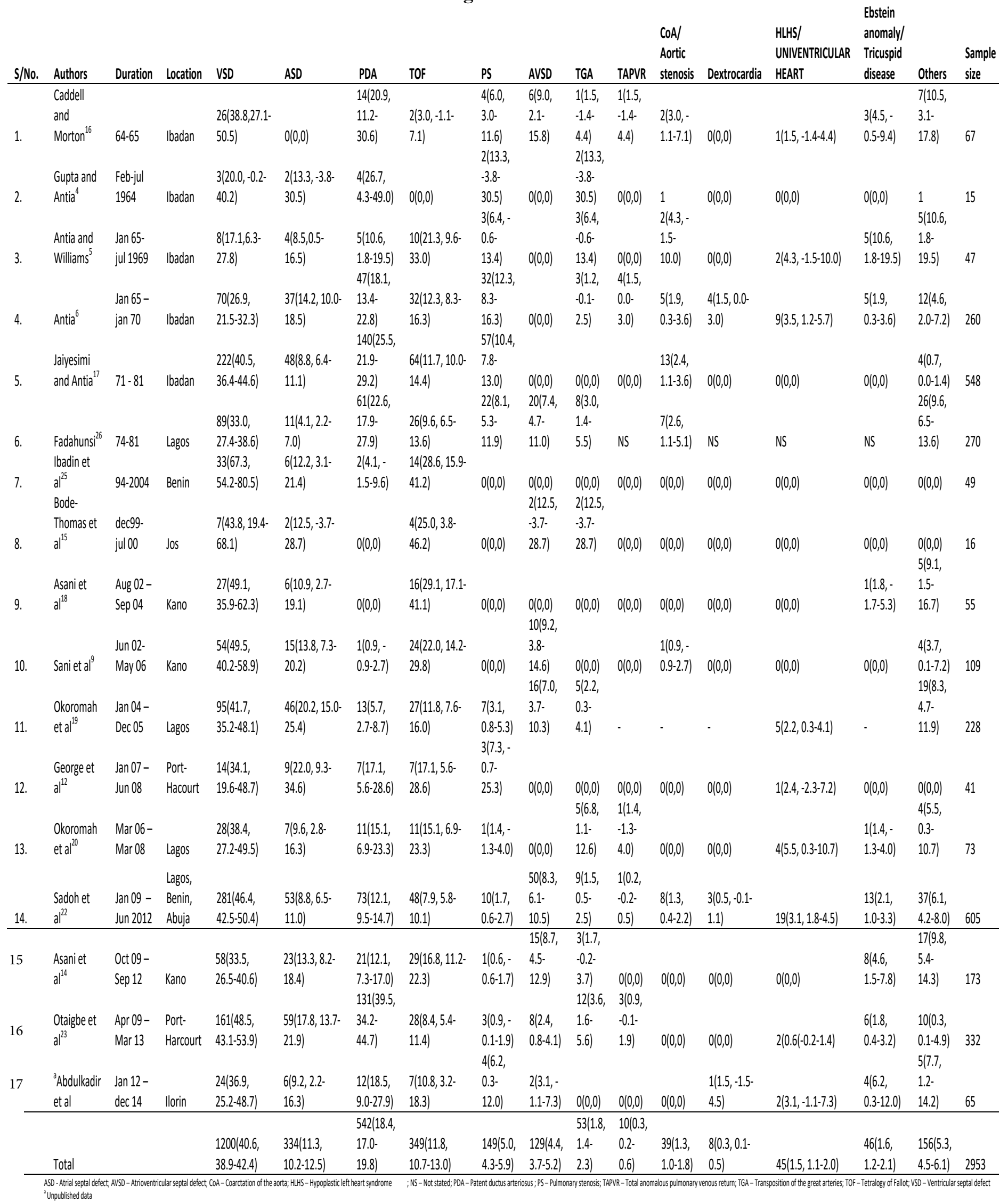


The included studies represent a total of 2,953 children with congenital heart disease. Figure 3 shows the pooled proportions of the 6 major heart defects in all the studies reviewed.

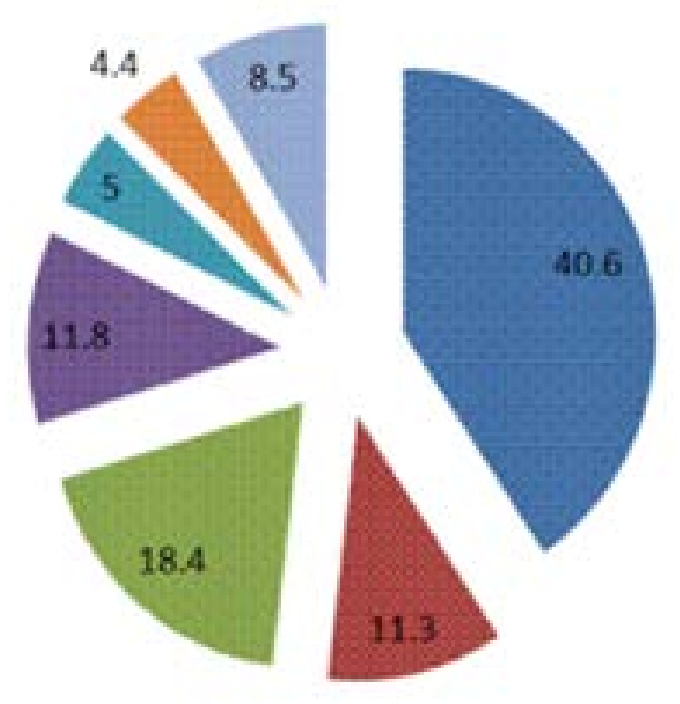

Figure 3: Pooled proportions of major congenital heart diseases (1964-2015) ASD - Atrial septal defect; AVSD - Atrioventricular septal defect; PDA - Patent ductus arteriosus; PS Pulmonary stenosis; TOF - Tetralogy of Fallot; VSD - Ventricular septal defect

\section{Ventricular septal defects (VSD)}

This was the commonest defect in all but two of the studies reviewed and constituted $40.6 \%$ (95\% CI 38.9-42.4) of all congenital heart disease. The burden of VSD among children with congenital heart disease ranged from a low of $17.1 \%$ in Ibadan $^{5}$ to a high of $67.3 \%$ in Benin. ${ }^{25}$ Merging the data countrywide over the five decade period, there has been a progressive increase in the contribution of VSD to the burden of congenital heart diseases with an average of $27.5 \%$ in the years $1964-1969$ and $55.8 \%$ between 2010 and 2014. The trend line (Figure 4) derived further depicts a steady rising proportion of VSD among children over the period.

\section{Patent ductus arteriosus (PDA)}

This was the identified congenital heart disease in 18.4\% (95\% CI 17.0-19.8) of the children and was the secondcommonest acyanotic defect in nine of the 17 studies reviewed with proportions ranging from $0.0 \%$ to $39.5 \%$ (Table 1). The trend analysis shows wide variations in the relative proportion of PDA over the decades but the overall trend line shows a slight decline (Figure 4). 


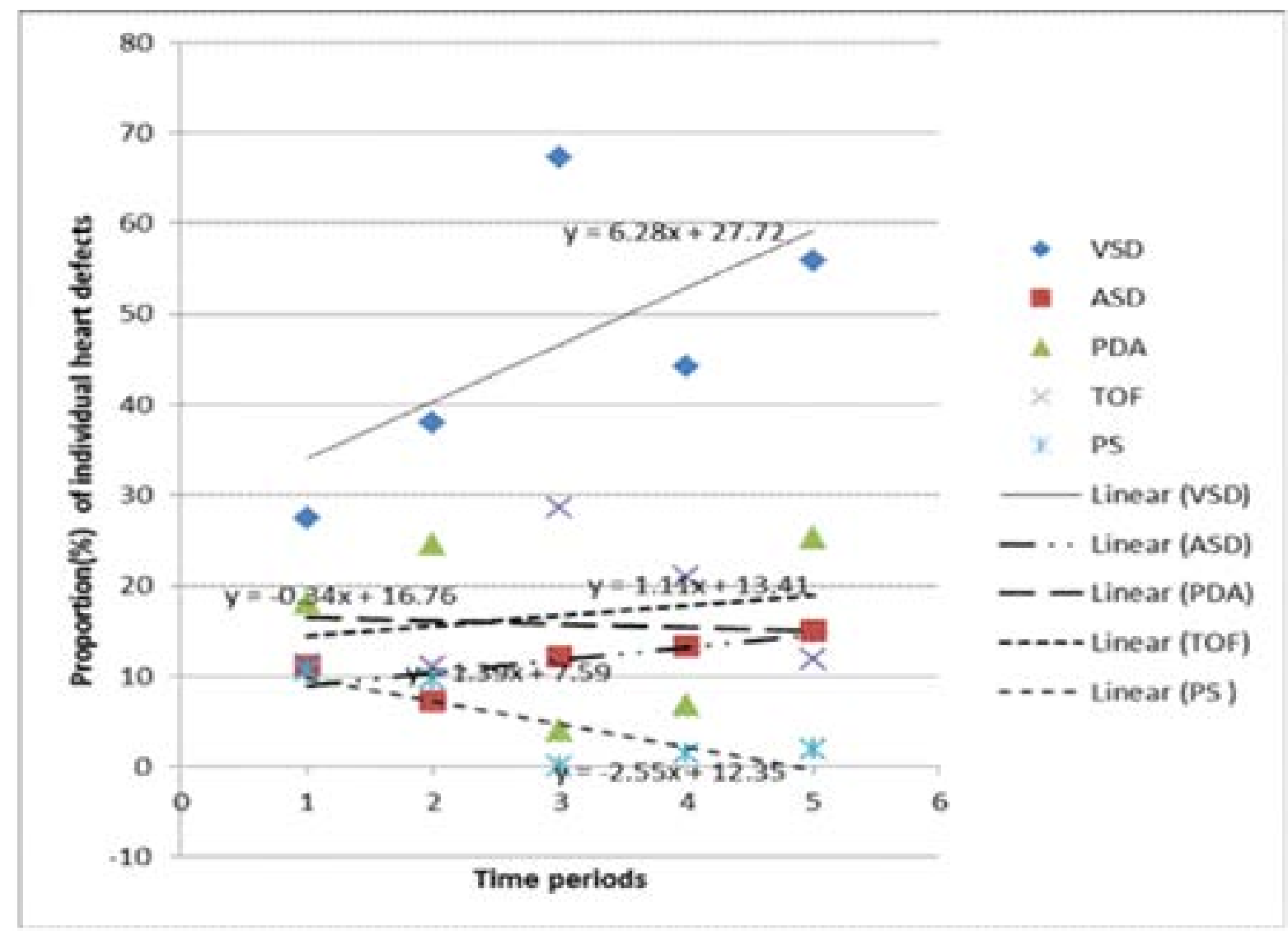

Figure 4: Trend analysis of proportions of the major heart defects over the study period (Time periods: 1-1965 to 1969; 2-1970 PubMed to 1979; 3-1990 PubMed to 1999; 4-2000 PubMed to 2009; 5- 2010 PubMed to 2015)

\section{Atrial septal defects (ASD)}

This was the second commonest acyanotic defect in seven of the 17 studies and was responsible for $11.3 \%$ (95\% CI 10.2-12.5) of all congenital heart diseases (Table 1). Overall it was the fourth commonest congenital heart disease. The highest relative proportion was $22.0 \%$ recorded by George et $\mathrm{al}^{12}$ in 2008 (Table 1). There is a gradually rising relative proportion of ASD among children with congenital heart disease in Nigeria (Figure 3).

\section{Tetralogy of Fallot (TOF)}

Tetralogy of Fallot was the commonest cyanotic congenital heart disease in all the studies, except the work of Gupta and Antia in 1967 (Table 1). It accounted for $11.8 \%$ (95\% CI 10.7-13.0) of all congenital heart diseases (Table 1). Relative proportion ranged from $0.0 \%$ to $29.1 \%$ in studies conducted in Kano. Over the period of the review, TOF accounted for $11.3 \%, 11.0 \%, 28.6 \%$, $17.0 \%$ and $9.5 \%$ of all congenital heart diseases during the periods 1964-1969, 1970-1979, 1990-1999, 2000-2009 and 2010-2014 respectively. The trend diagram (Figure 4) depicts a rising proportion of TOF over the review period.

\section{Pulmonary stenosis (PS)}

Pulmonary stenosis occurred in between $0.0 \%$ and $13.3 \%$ of congenital heart diseases in Nigeria (Table 1). The highest contributions were recorded in Ibadan in the period between 1964 and 1981 (Table 1). The trend diagram (Figure 3) depicts falling relative proportion of PS over the study period.

Other heart diseases were uncommon and their relative frequencies are shown in Table 1.

\section{Regional distribution of major heart defects}

Figure 5 represents pooled data from all the studies distributed according to geopolitical regions. With all defects pooled to the defined regions (South-South, South-West, 
North-West, North-Central), the commonest defect was the VSD in all regions, however the second common- est defect was PDA in all regions except the North-West where TOF was the second commonest lesion.

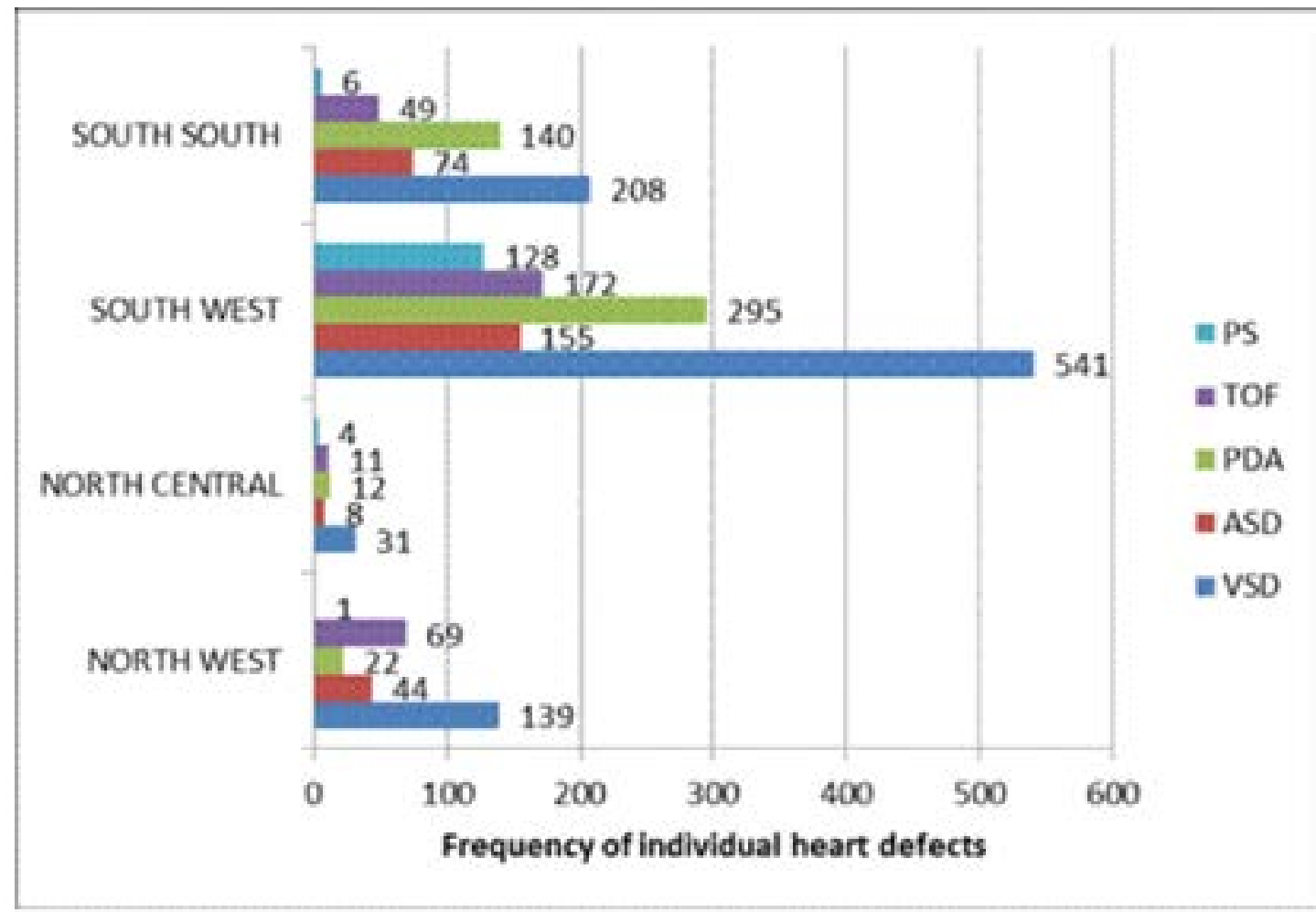

\section{Figure 5: Distribution of major congenital heart diseases according to geopolitical zones of the country (Multicentre study excluded from this analysis). Nostudies reported from North-East and South East.}

\section{Time trend analysis of the heart defects}

The overall trend lines demonstrate some changes in the relative proportion of the individual defects. (Figure 3) The greatest rise in burden of congenital heart defects was seen among children with VSD. There was an average of $6 \%$ increase in the burden of VSD for every time period. There were minor changes in the other heart defects with an apparently slight increase in burden of tetralogy of Fallot and atrial septal defects and a slight decrease in burden of patent ductus arteriosus. There was an average of a $2.6 \%$ reduction in the burden of pulmonary stenosis per time period.

\section{Discussion}

This systematic review provides critical data on trends in the spectrum of CHD among children in Nigeria and represents the first truly nationwide data examining the patterns and the influence of regional differences and time on the spectrum of CHD. The distribution of individual congenital heart defects appear to be changing in Nigeria with an apparent increase in the incidence of VSD and a decline in pulmonary stenosis. Ventricular septal defects have been shown globally to be the commonest congenital heart diseases seen in children., ${ }^{2,27}$

The reasons for the predominance of VSD are unclear. Despite this, there have been wide variations in the contribution of VSD to overall prevalence of congenital heart diseases. Earlier studies had reported prevalence of between 20 and 29\%., ${ }^{2,8}$ However, more recent reports globally have suggested that VSD are commoner than previously reported with the burden as high as $50 \%$ (in combination with other defects). ${ }^{27,29}$ The current review demonstrated an overall proportion of $40.6 \%$ which is similar to the $50 \%$ reported above. Although the current study did not explore age distribution of the patients, it is now known that actual prevalence of these congenital 
heart lesions is dependent on the age at which screening is conducted. ${ }^{27,29}$ The earlier work of Antia and Williams recruited children at birth and followed them up till early childhood and expectedly demonstrated that VSD was the commonest CHD. ${ }^{5}$ This contrasted with the work of Gupta and Antia which was a necropsy based study that reported TOF to be the commonest $\mathrm{CHD} .{ }^{4}$ This demonstrates the influence of study methodology which should be a prime consideration in studies examining spectrum of CHD. The current study has also demonstrated a rising burden of VSD among children in Nigeria with a $6.3 \%$ increase in the burden of VSD for every decade studied.

To a large extent, the "rising burden" of VSD globally has been attributed to increasing availability of facilities and expertise for early diagnosis of VSD. As such, small defects that would have closed in later childhood are diagnosed from echocardiographic studies in infancy. This has been documented by several authors. ${ }^{2,27,29}$ Hence, the extent to which these variations recorded represent "true" changes in the occurrence rather than detection rates of VSD will require further exploration. There were no regional differences in the proportions of VSD in this study. The enormous burden of VSD is exemplified by considering the incidence of CHD in Nigeria of 3.5 per 1000 live births with an estimated 7.17 million live births (UNICEF 2013) annually in Nigeria., ${ }^{40}$ This is equivalent to an estimated 25,106 children being borne with a congenital heart disease annually of which 14,009 will have a VSD (based on most recent relative proportion of $55.8 \%$ of CHD being VSD in the 2010-2014 period reviewed). At the current birth rate and disease rates this number should increase to 15,590 children being borne annually with a VSD in the next decade.

The current review has demonstrated apparent regional differences in the other major congenital heart diseases. In the North West region there is a higher prevalence of ASD and TOF as compared to PDA. A large part of these variations in burden of ASD and PDA may be explained by study design. Studies that include a lot of younger children will tend to report higher incidence of PDA as against studies that recruit a larger number of older children/ adolescents; an age group in which ASD begin to manifest with symptoms. Furthermore, it has been shown that some cardiologists may misclassify the foramen ovale as an ostium secundum ASD or vice versa thus affecting the reported burden. Also, there is inconsistency in how children with multiple lesions are reported. Some authors may report them as individual lesions while others report them as combined lesions. Hence, it is conceivable that when ASD are associated with other "more serious" abnormalities they may be under reported. Nevertheless, the consistency of reports of ASD being far commoner than PDA in Northern Nigeria make a compelling case for researchers to explore this relationship in larger well designed studies. This is especially as several authors have demonstrated racial, ethnic and environmental differences in incidence and spectrum of CHD in other climes. ${ }^{31-33}$

Tetralogy of Fallot has been shown consistently in most studies globally to be the commonest cyanotic congenital heart disease with transposition of the great arteries being a far second. ${ }^{1,2,27}$ This is corroborated by the findings of this study. Other CHD featured in numbers too small to make valid inferences from. Nevertheless, the burden of TGA, tricuspid disease and hypoplastic left heart syndrome appear to be quite similar and together constitute $4.9 \%$ of all congenital heart defects. The similarities in clinical presentation of these three cyanotic conditions make it imperative that facilities and expertise to diagnose them early should be readily available in most centres. While the trend analysis shows a rising trend for VSD over the period, proportions for other CHD have remained essentially static or reduced. This phenomenon may be accounted for by the rising number of cases of VSD being recorded as proportions rather than actual numbers were the comparisons made in the current study. Nevertheless, some authors have implicated reducing burden of some risk factors for some of these conditions, such as reducing occurrence of rubella among mothers. $^{34}$

\section{Conclusion}

VSD remains the commonest CHD in Nigeria. Patent ductus arteriosus is the second commonest CHD though in pockets of areas ASD and TOF may be commoner. There appears to be a trend towards increasing burden of VSD in Nigeria.

\section{Limitations}

The possibility of recruitment of the same patients in studies from the same centre with overlap exists. Such 
duplication of patients were minimised by ensuring studies that apparently had the same data were excluded from the review.

\section{Competing interests}

The authors declare no conflict of interest.

\section{References}

1. Mitchell SC, Korones SB, Berendes HW. Congenital heart disease in 56,109 births. Incidence and natural history. Circulation 1971;43(3):323-32.

2. Allen HD, Driscoll DJ, Shaddy RE, Feltes TF. Moss \& Adams' Heart Disease in Infants, Children, and Adolescents: Including the Fetus and Young Adult. 8th ed. Philadelphia: Lippincott Williams \& Wilkins, 2013.

3. Bernstein D. Congenital heart disease. In: Kliegman RM, Stanton BF, St-Geme J, Schor N, Behrman RE eds. Nelson Textbook of Pediatrics, 19th edition. Philadelphia: Saunders. 2011.pp 1549-605.

4. Gupta B, Antia AU. Incidence of congenital heart disease in Nigerian children. Br Heart J 1967;29(6):906-9.

5. Antia AU, Williams AO. Congenital heart disease in Nigeria. Necropsy study of 47 cases. Br Heart J 1971;33(1):133-7.

6. Antia AU. Congenital heart disease in Nigeria. Clinical and necropsy study of 260 cases. Arch Dis Child 1974;49(1):36-9.

7. Fink JC, Schmid CH, Selker HP. A decision aid for referring patients with systolic murmurs for echocardiography. J Gen Intern Med 1994;9(9):479-84.

8. Cheitlin MD, Armstrong WF, Aurigemma GP et al. ACC/AHA/ASE 2003 Guideline Update for the Clinical Application of Echocardiography: summary article. A report of the American College of Cardiology/American Heart Association Task Force on Practice Guidelines (ACC/AHA/ASE Committee to Update the 1997 Guidelines for the Clinical Application of Echocardiography). J Am Soc Echocardiogr 2003;16(10):1091-110.

9. Sani MU, Mukhtar-Yola M, Karaye KM. Spectrum of congenital heart disease in a tropical environment: an echocardiography study. J Natl Med Assoc2007;99(6):665-9.

10. Ejim EC, Ike SO, Anisiuba BC, etal. Ventricular septal defects at the University of Nigeria Teaching Hospital, Enugu: a review of echocardiogram records. Trans $\mathrm{R}$ Soc Trop Med Hyg 2009;103(2):159-61.

11. Ekure EN, Animashaun A, Bastos M, Ezeaka VC.
Congenital heart diseases associated with identified syndromes and other extra-cardiac congenital malformations in children in Lagos. West Afr J Med 2009;28(1):33-7.

12. George IO, Frank-Briggs AI. Pattern and clinical presentation of congenital heart diseases in Port-Harcourt. Niger J Med 2009;18(2):211-4.

13. Chinawa JM, Eze JC, Obi I, et al. Synopsis of congenital cardiac disease among children attending University of Nigeria Teaching Hospital Ituku Ozalla, Enugu. BMC Res Notes 2013;6:475.

14. Asani MO, Aliyu I, Kabir H. Profile of congenital heart defects among children at Aminu Kano Teaching Hospital, Kano, Nigeria. Journal of Medicine in the Tropics 2013;15(2):131-34.

15. Bode-Thomas F, Okolo SN, Ekedigwe JE, Kwache IE, Adewunmi O. Paediatric Echocardiography in Jos University Teaching Hospital: Problems, Prospects and Preliminary Audit. Nig J Paediatr 2003;30(4):143-49.

16. Caddell JL, Morton P. The pattern of congenital heart disease in Yoruba children of Western Nigeria. Am Heart J 1967;73(3):431-2.

17. Jaiyesimi F, Antia AU. Congenital heart disease in Nigeria: a ten-year experience at $\mathrm{UCH}$, Ibadan. Ann Trop Paediatr 1981;1(2):77-85.

18. Asani MO, Sani MU, Karaye KM, et al. Structural heart diseases in Nigerian children. Niger J Med 2005;14(4):3747.

19. Okoromah CA, Ekure EN, Ojo OO, Animasahun BA, Bastos, MI. Structural heart disease in children in Lagos: profile, problems and prospects. Niger Postgrad Med J 2008;15(2):82-8.

20. Okoromah CA, Ekure EN, Lesi FE, Okunowo WO, Tijani BO, Okeniyi JC. Prevalence, profile and predictors of malnutrition in children with congenital heart defects: a case-control observational study. Arch Dis Child 2011;96(4):354-60.

21. Sadoh WE, Sadoh AE. Serum zinc values in children with congenital heart disease. Afr Health Sci 2013;13(3):601-6.

22. Sadoh WE, Uzodimma CC, Daniels Q. Congenital heart disease in Nigerian children: a multicenter echocardiographic study. World J Pediatr Congenit Heart Surg 2013;4(2):172-6.

23. Otaigbe BE, Tabansi PN. Congenital heart disease in the Niger Delta region of Nigeria: a four-year prospective echocardiographic analysis. Cardiovasc J Afr 2014;25:1-4. 
24. Kolo PM, Adeoye PO, Omotosho AB, Afolabi JK. Pattern of congenital heart disease in Ilorin, Nigeria. $\mathrm{Ni}$ ger Postgrad Med J 2012;19(4):230-4.

25. Ibadin MO, Sadoh WE, Osarogiabon W. Congenital heart diseases at the University of Benin Teaching Hospital. Nig Journal Paediatr 2007;32(2):29-32.

26. Fadahunsi HO. Congenital heart disease in Nigerian children: a study from the Lagos University Teaching Hospital. West Afr J Med 1987;6:21-30.

27. Hoffman JIE, Kaplan S. The incidence of congenital heart disease. J Am Coll Cardiol 2002;39(12):1890-900. 28. Keith JD, Rowe RD, Vlad P. Heart Disease in Infancy and Childhood. New York: Macmillan, 1967.

29. Roguin N, Du ZD, Barak M, Nasser N, Hershkowitz S, Milgram E. High prevalence of muscular ventricular septal defect in neonates. J Am Coll Cardiol 1995;26(6):15458.

30. UNICEF. State of The World's Children 2015 Country Statistical Information. New York: UNICEF, 2013.
31. Canfield MA, Honein MA, Yuskiv N, et al. National estimates and race/ethnic-specific variation of selected birth defects in the United States, 1999-2001. Birth Defects Research Part A: Clinical and Molecular Teratology 2006;76(11):747-56.

32. Freeman SB, Bean LH, Allen EG, et al. Ethnicity, sex, and the incidence of congenital heart defects: areport from the National Down Syndrome Project. Genet Med 2008;10(3):173-80.

33. Nikyar B, Sedehi M, Mirfazeli A, Qorbani M, Golalipour MJ. Prevalence and Pattern of Congenital Heart Disease among Neonates in Gorgan, Northern Iran (2007-2008). Iranian Journal of Pediatrics 2011;21(3):307-12. 34. Ekure EN, Adeyemo AA. Clinical epidemiology and management of heart defects in a developing country. In: Muenke M, Kruszka PS, Sable CA, Belmont JW, eds. Congenital Heart Disease: Molecular Genetics, Principles of Diagnosis and Treatment. Basel: Karger, 2015:46-56. 